\title{
The Relationship Between Maternal Overprotection, Adolescent Internalizing and Externalizing Problems, and Psychological Need Frustration: A Multi-Informant Study Using Response Surface Analysis
}

Stijn Van Petegem ${ }^{1}$, Jean-Philippe Antonietti ${ }^{1}$, Cindy Eira Nunes ${ }^{1}$, Evie Kins ${ }^{2}$ \& Bart Soenens $^{2}$

\footnotetext{
${ }^{1}$ Family and Development Research Center (FADO), Institute of Psychology, University of Lausanne, Switzerland; ${ }^{2}$ Department of Developmental, Personality and Social Psychology, Ghent University, Belgium
}

Acknowledgments. The authors would like to thank the adolescents and parents who kindly accepted to participate in the study, as well as the master thesis students who helped in the data collection.

Data Sharing Declaration. The datasets analyzed during the current study are available in the FORS repository (https://forsbase.unil.ch/project/study-public-overview/16244/0/), and are available upon request.

Funding. This research was supported by a grant from the Special Research Fund of Ghent University (Belgium) and a grant from the Swiss National Science Foundation (FNS n ${ }^{\circ}$. $\left.10001 C_{-} 179455 / 1\right)$.

This article may not exactly replicate the final version published in the journal. The final version is in press in Journal of Youth and Adolescence.

The exact reference is: Van Petegem, S., Antonietti, J.-P., Eira Nunes, C., Kins, E., \& Soenens, B. (in press). The relationship between maternal overprotection, adolescent internalizing and externalizing problems, and psychological need frustration: A multiinformant study using response surface analysis. Journal of Youth and Adolescence. doi: 10.1007/s 10964-019-01126-8 


\begin{abstract}
Parents and adolescents may hold discrepant views about parents' behaviors, which may be related to adolescent maladjustment. The goal of the present investigation was to examine associations between overprotective parenting and adolescents' internalizing and externalizing problems and the frustration of their psychological needs (for autonomy, relatedness and competence), thereby considering both congruence and incongruence in adolescents' and mothers' reports of overprotective parenting. Our sample consisted of 402 mother-adolescent dyads ( $M$ adolescent age $=16.8$ years, $63 \%$ female), who reported upon the mothers' overprotective parenting. In addition, adolescents filled out questionnaires assessing their internalizing and externalizing problems and psychological need frustration. Data were analysed using polynomial regressions with response surface analysis. Results showed evidence for a linear, additive relationship between adolescents' and mothers' reports of overprotective parenting, and adolescents' internalizing and externalizing symptoms and relatedness and competence frustration. That is, higher scores in adolescents' and mothers' ratings of overprotective parenting were associated with more maladjustment and more need frustration. Moreover, results indicated that incongruence between adolescents' and mothers' reports related to more externalizing problems and more autonomy and relatedness frustration, and this was especially the case when adolescents perceived higher levels of overprotection than what was reported by mothers. These results underscore the importance of considering multiple perspectives when studying the dynamics involved in overprotective parenting.
\end{abstract}




\section{Introduction}

In developmental literature on parenting, parental involvement is generally assumed to be positive for children's and adolescents' functioning (e.g., Barger, Kim, Kuncel, \& Pomerantz, 2019). Importantly, however, such involvement should be adjusted to the child's developmental status (Grusec \& Davidov, 2010). In the case of parental overprotection, parents provide a level of protection that is excessive, taking into consideration the developmental level of the child (Thomasgard, Metz, Edelbrock, \& Shonkoff, 1995). Overprotection may backfire because it interferes with the development of children's resilience and coping skills, potentially causing anxiety and other mental health problems (Segrin, Woszidlo, Givertz, \& Montgomery, 2013). In that respect, recent research among children and adolescents confirms that parental overprotection is a risk factor for psychosocial difficulties, including lowered self-esteem and internalizing and externalizing problems (e.g., Roelofs, Meesters, ter Huurne, Bamelis, \& Muris, 2006). Similarly, past research found that perceived overprotective parenting thwarted college students' psychological needs for autonomy, relatedness, and competence (Schiffrin et al. 2019). Most of these studies, however, are based solely upon single-informant reports of overprotective parenting. This is unfortunate, as adolescents and parents may differ substantially in their consideration of whether their parents' protection is excessive or not (Korelitz \& Garber, 2016). Hence, this study used a multi-informant design to examine whether discrepancies in adolescents' versus mothers' reports of overprotective parenting are associated with adolescents' internalizing and externalizing problems and their psychological need frustration. This is done through the use of response surface analysis (Edwards, 2002), an analytical tool particularly apt for the consideration of congruence and incongruence in the reports of different informants (Barranti, Carlson, \& Côté, 2017).

\section{Parental Overprotection During Adolescence}


Adolescence is a developmental period characterized by considerable changes, with adolescents spending increasing amounts of time outside the parental home, exploring different identity alternatives, and striving for more independence and self-reliance (e.g., Smetana, Campione-Barr, \& Metzger, 2006). As a consequence, there is an increased risk during adolescence that parents are involved in their offspring's life in ways that do not meet their developmental needs (Guttman \& Eccles, 2007). During adolescence, parental overprotection can manifest through a variety of parenting practices (Brenning, Soenens, Van Petegem, \& Kins, 2017), such as when parents constantly warn about potential dangers and are excessively preoccupied about the adolescent's safety (Grüner, Muris, \& Merkelbach, 1999), when they solve problems prematurely by providing help when this is not requested (Segrin, Givertz, Swaitkowski, \& Montgomery, 2015), or when they intrude upon the adolescent's privacy (Hawk, Keijsers, Hale III, \& Meeus, 2009).

While there is a long-standing tradition of examining parental overprotection in samples of children with a clinical diagnosis of mental health problems (e.g., Hudson \& Rapee, 2001; Parker, 1983) or with a physical disability (e.g., Holmbeck et al., 2002), recent research increasingly began to examine the correlates of parental overprotection in samples of adolescents and young adults from the general population. It should be noted, however, that most of these studies focused on college and university students. These studies consistently indicate that a higher degree of parental overprotection is associated with more internalizing problems. For instance, in a sample of university students, overprotective parenting was found to be associated with lower psychological well-being and a higher prescription of medication for anxiety or depression (LeMoyne \& Buchanan, 2011). Similarly, higher levels of parental overprotection during young adulthood were found to relate to lower psychosocial adjustment, including higher levels of distress, lowered self-esteem, excessive worries about relationships, and unassertive interpersonal behavior (Rousseau \& Scharf, 2015). Although 
less studied, there is also research indicating that overprotective parenting is associated with more externalizing problems. For instance, in a study among 9-to-12-year old children higher scores on overprotective and anxious parenting were found to relate to more aggression (Roelofs et al., 2006), whereas another study among adolescents indicated positive associations between overprotective parenting and delinquent and aggressive behaviors (Muris, Meesters \& van den Berg, 2003).

Recent research used Self-Determination Theory (Ryan \& Deci, 2017) for explaining why overprotective parenting is harmful for adolescents' and young adults' psychosocial adjustment (Schiffrin et al., 2014). A central tenet in Self-Determination Theory is that the satisfaction (vs. frustration) of individuals' basic psychological needs is critical for one's well-being and mental health. Self-Determination Theory distinguishes between three psychological needs - the need for autonomy (i.e., experiencing a sense of volition and personal choice), the need for relatedness (i.e., feeling connected to important others), and the need for competence (i.e., feeling confident in one's capacities; Ryan \& Deci, 2000). Frustration of these psychological needs manifests in experiences of pressure and coercion (autonomy need frustration), inadequacy and failure (competence need frustration), and loneliness and social alienation (relatedness need frustration). A large body of research showed that the satisfaction of these needs is predictive of well-being and better psychosocial adjustment, and that the frustration of these needs relates to ill-being and risk for psychopathology (Ryan, Deci, \& Vansteenkiste, 2016). Further, it was shown that the frustration of these three needs explained the associations between overprotective parenting and young adults' maladjustment (Schiffrin et al., 2014). That is, when parents are overprotective, their involvement may be experienced as intrusive and unwanted, thus threatening the need for autonomy. In addition, excessively helping the adolescent in solving his/her problems may invalidate adolescents' sense of competence, as it may signal parents' 
lack of trust in adolescents' capacities to face difficulties. Finally, overprotection also may threaten the need for relatedness, because adolescents may feel that their parents' love depends on loyalty and enforced reliance on parental advice, thus reducing the quality of the parent-child bond (Soenens, Vansteenkiste, \& Luyten, 2010). Further, overprotective practices have been found to negatively affect the quality of the parent-child communication (e.g., Segrin, Woszidlo, Givertz, Bauer, \& Murphy, 2012) and the healthy development of peer relationships more generally (e.g., van Ingen et al., 2015). The frustration of these needs, in turn, has been found to predict more symptoms of depression and anxiety, and less satisfaction with life (Schiffrin et al., 2014).

Although informative, each of the previously discussed studies primarily drew upon adolescents' own perceptions of parental overprotection. This is a valid approach, as children generally report more accurately upon parenting behaviors as compared to parents (e.g., when considering associations with observations of parenting), and because children's perceptions of parenting ultimately determine children's well-being and behavior (Hendriks, Van der Giessen, Stams, \& Overbeek, 2018). Nevertheless, at the same time, parents and adolescents often disagree about many family processes, including their perceptions of conflict in the family (De Los Reyes, Goodman, Kliewer, \& Reid-Quinones, 2010), their beliefs about the legitimacy of parental authority (Smetana, Crean, \& Campione-Barr, 2005), and their perceptions of the quality of family communication (De Los Reyes, Ohannessian, \& Laird, 2016). For instance, one study found that adolescents generally view the family more negatively than their parents (in terms of satisfaction and communication; Ohannessian \& De Los Reyes, 2014). In addition, such discrepancies between family members' perceptions of these family dynamics seem to have important implications for adolescent adjustment (e.g., Rote \& Smetana, 2016). For example, a longitudinal study showed that greater discrepancies in adolescents' versus mothers' perceived openness of family communication were predictive 
of increases in adolescents' externalizing problems (in terms of alcohol use, binge drinking and aggressive behaviour) across time (Ohannessian, 2012).

There is a dearth of studies examining the implications of similarities and differences in parents' versus adolescents' reports of overprotective parenting for adolescents' functioning. This is unfortunate because the concept of overprotective parenting, by definition, implies a discrepancy between what parents provide (in terms of protection) and what children need developmentally (Holmbeck et al., 2002). Thus, parental overprotection is an inherently subjective construct and it may be especially detrimental when there is a discrepancy between adolescents' experiences versus parents' reports of overprotective parenting. The main goal of the present contribution, therefore, was to examine implications of discrepancies in adolescents' versus parents' reports of overprotective parenting for adolescents' internalizing and externalizing problems and for their psychological needs-based experiences. Thereby, the present study made use of polynomial regression approach with response surface analysis.

\section{A Response Surface Analysis Approach for Studying Informant Discrepancies}

When studying the implications of informant discrepancies, researchers often calculate a difference score, which is then used as a predictor of an outcome variable. For instance, in the present study, adolescent scores of overprotection could be subtracted from the maternal scores, and this difference score could be used as a predictor of adolescents' internalizing problems. However, difference scores have several important methodological problems (Edwards, 2002; Laird \& De Los Reyes, 2013). For example, they do not provide information about the absolute level of the variable of interest: a low difference score only would indicate that mothers and adolescents agree in their ratings of parental overprotection, without yielding any information about whether mothers and adolescents report high or rather low levels of parental overprotection. Thus, difference scores are ambiguous in their interpretation, as they 
collapse data from distinct informants (i.e., adolescent-reported overprotection and motherreported overprotection) into a single score (i.e., the discrepancy between adolescent-reported and mother-reported overprotection). As a consequence, the use of difference scores also reduces the relationship between the two component measures (i.e., adolescent-reported and mother-reported overprotection) and the outcome variable (e.g., internalizing problems) from a three-dimensional to a two-dimensional relationship, thus oversimplifying the relationship between the predictors and the outcome variable. Further, difference scores are less reliable than the component measures that are used for calculating the difference score (Edwards, 2002). For an extensive discussion of the limitations of difference scores, and of other alternatives for difference scores (e.g., absolute and squared difference scores, and latent difference scores) and their limitations, the reader is referred to de Haan, Prinzie, Sentse, and Jongerling (2018) and Edwards (2002).

As an alternative to difference scores, it is proposed to use polynomial regression with response surface analysis (RSA; Edwards, 2002). This approach assesses and visualizes the relationship between different types of (in)congruence and the outcome variable, by treating the relationship between the two component measures (in this case, adolescent-reported and mother-reported overprotection) and the outcome (e.g., internalizing problems) as a threedimensional surface (see also Schönbrodt, Humberg, \& Nestler, 2018). When using RSA, congruence is not considered as a single score or a point, but as a line reflecting correspondence between the two component measures. This line of congruence (LOC) represents the degree to which agreement between the two respondents is associated with the outcome variable. This relationship may be either linear (e.g., congruent and high scores of reports of overprotection would relate to more internalizing problems, whereas congruent but low scores of overprotection would relate to fewer internalizing problems) or curvilinear (e.g., congruently high scores and congruently low scores of overprotection relate to more 
internalizing problems, whereas congruently moderate levels of overprotection relate to fewer internalizing problems). Further, the line of incongruence (LOIC) examines whether and how the discrepancy between two informants is related to an outcome variable. This line may either be linear, which would indicate that incongruence in one direction is especially predictive of the outcome variable (e.g., adolescents' reports exceeding parents' reports would relate to more internalizing problems), or curvilinear, which would indicate that incongruence as such, regardless of the direction, is predictive of the outcome variable (e.g., discrepancies in adolescents' vs. parents' reports relate to more internalizing problems, regardless of whether adolescents' or parents' reports are highest; Barranti et al., 2017).

To illustrate, Figure 1 displays an example depicting the hypothetical relationship between the two component measures (adolescent-reported and mother-reported overprotection) and an outcome variable. The X- and Y-axes (adolescent-reported and mother-reported overprotection, respectively) vary from negative to positive values, and 0 reflects the scale midpoint. The response surface depicts the expected values for the outcome measure for all possible combinations of the two component measures (Barranti et al., 2017). The LOC depicts the line of perfect agreement between the component measures (i.e., $x=y$ ). Thus, dyads along this line have scores on adolescent-reported and mother-reported overprotection that are exactly the same. In the hypothetical example of Figure 1, there is a linear (and positive) effect along the LOC, indicating that congruently high scores on adolescent-reported and mother-reported overprotection relate to higher scores on the outcome variable, whereas congruently low scores on adolescent-reported and motherreported overprotection relate to lower scores on the outcome variable. The LOIC represents cases where the values of one component measure are the opposite of values of the other component measure (i.e., $\mathrm{x}=-\mathrm{y}$ ). Thus, dyads along this line have scores for adolescentreported overprotection that are high, whereas scores for mother-reported overprotection are 
low (e.g., adolescent-reported overprotection is 1 standard deviation above the midpoint, whereas mother-reported overprotection is 1 standard deviation below the midpoint), or vice versa. In the hypothetical example of Figure 1, there is a linear (and positive) effect along the LOIC, indicating that dyads with relatively high scores on adolescent-reported overprotection and relatively low scores on mother-reported overprotection are expected to have higher scores on the outcome measure, whereas dyads with relatively low scores on adolescentreported overprotection and relatively high scores on mother-reported overprotection are expected to have lower scores on the outcome measure.

A recent study used RSA to examine whether discrepancies in parents' versus adolescents' reports of family chaos and routines are related to adolescents' psychological adjustment (Human, Dirks, DeLongis, \& Chen, 2016). Their research indicated that adolescents' perceptions of family functioning were a stronger predictor of adolescent adjustment than the parents' perceptions. More importantly, both congruence and incongruence in adolescents' and parents' reports were predictive of adolescents' adjustment. Specifically, congruently negative perceptions of the family (in terms of chaos and family routines) were associated with more maladjustment among adolescents. In addition, incongruence also related to more maladjustment, and especially when adolescents' reports were more negative than parents' reports of the family's functioning (i.e., they mainly found evidence for a linear effect of incongruence). These results underscore the potential of using RSA for understanding the implications of congruence and incongruence in views of family dynamics for adolescent adjustment.

\section{The Present Study}

As past research on the correlates of overprotective parenting typically drew upon single-informant data, the present contribution aimed to examine whether congruence and incongruence in adolescents' versus mothers' reports of overprotective parenting was 
predictive of adolescents' internalizing and externalizing problems and psychological need frustration. First, it was expected that higher scores on adolescent- and mother-reported overprotective parenting would relate to more adolescent maladjustment (i.e., more internalizing and externalizing problems, and more need frustration). This relationship was expected to be linear, as previous research (e.g., Schiffrin et al., 2014) also found evidence for linear relationships between perceived overprotective parenting and adolescents' and young adults' maladjustment. Further, it was also expected that incongruence would relate to adolescents' adjustment. Specifically, a linear effect of incongruence was expected, as overprotective parenting especially would be harmful when parents' involvement is experienced as excessive (Holmbeck et al., 2002). Thus, it was hypothesized that, when adolescents' reports of overprotection exceeded their mothers' reports, they would be more likely to report higher levels of internalizing and externalizing problems and psychological need frustration, as such an incongruence would be reflective of a discrepancy between the degree of protection provided by mothers and the adolescent's developmental needs.

\section{Method}

\section{Sample and Procedure}

For the present study, two independent data sets were combined. The first data set (subsample A) was gathered through the use of paper-and-pencil questionnaires distributed in three secondary public schools from middle-sized municipalities (ranging in size between 20.000 and 100.000 inhabitants) in the Dutch-speaking part of Belgium (Flanders). Research assistants visited the schools and administered questionnaires in 10th, 11th and 12th grade. Prior to participation, students were informed about the anonymous treatment of the data and the voluntary nature of participation. Passive informed consent was obtained from the parents, and active informed consent from the adolescents. No adolescents or parents refused participation in the study. Adolescents filled out questionnaires during a regular class period 
in the presence of the research assistant. Mothers of the participants also received questionnaires, and they were invited to fill these out and return the questionnaires in a closed envelope, together with a completed informed consent form. The adolescent questionnaires were matched with the mother questionnaires using anonymized codes. In total, this subsample consisted of 261 adolescents and 176 mothers. However, as the analyses focus on similarities and differences in adolescent-reported versus mother-reported overprotection, only complete dyads were included in our analyses, resulting in a first subsample of 174 mother-adolescent dyads.

Subsample B was gathered in the context of a class on developmental psychology. After having received training, undergraduate students were instructed to invite an adolescent (from 10th, 11th, or 12th grade) and his/her mother to participate in the study. During a home visit, they explained the confidential treatment of the data, the voluntary nature of participation in the study, and they obtained active informed consents from the adolescent and mother. Then, they filled out paper-and-pencil questionnaires, in the presence of the undergraduate student. Again, data were matched using anonymized codes. In total, 246 adolescents and 242 mothers participated. However, due to problems matching some of the data, subsample B eventually consisted of 228 mother-adolescent dyads. The data of subsample B have been used in one previous research report (Brenning et al., 2017).

The total sample consisted of 402 mother-adolescent dyads. The adolescents $(63.2 \%$ girls) were on average 16.8 years old $(S D=.89$, range $=14-20$ years $)$. Most of the participants' parents were living together or married (81\%); $16 \%$ of the parents were separated, and in $2 \%$ of the cases the father had deceased. Mothers were on average 46.4 years old $(S D=3.7$, range $=37-59)$, and were all biological mothers. As for their highest educational level, $4 \%$ had not completed secondary education, $30 \%$ had completed secondary 
education, $52 \%$ had obtained a bachelor's degree (or an equivalent), and $14 \%$ a master's degree (or an equivalent) or higher.

\section{Measures}

Participants in subsample A and subsample B filled out all questionnaires, except for the questionnaires assessing internalizing and externalizing problems, which were only completed by participants in subsample A. Thus, while most analyses were performed on a sample of 402 dyads, analyses involving internalizing and externalizing problems were conducted on the subsample of 174 dyads.

Adolescent-reported maternal overprotection. Adolescents reported upon their perceptions of maternal overprotection through five subscales of the Multidimensional Overprotection Scale (MOPS; Kins \& Soenens, 2013). Each subscale consisted of five items, assessing five components of overprotective parenting, resulting in 25 items in total. The subscales assessed premature problem solving (e.g., "My mother tries to solve all of my problems for me without me having to do anything"), anxious rearing (e.g., "My mother shows me the possible risks in everything I do"), infantilization (e.g., "My mother is treating me in a childish way"), privacy invasion (e.g., "My mother makes comments about things that are none of her business like my clothes, hobbies, friends or music"), as well as general perceptions of overprotection (e.g., "My mother is too protective"). Items were rated on a 5point Likert-type scale, ranging from 1 (Completely untrue) to 5 (Completely true). Previous research (e.g., Brenning et al., 2017) revealed good psychometric properties in terms of convergent validity and reliability. In the present study, the scale had a good reliability as well $(\alpha=.90)$.

Mother-reported maternal overprotection. Mothers also reported upon their overprotection vis-à-vis the participating child. This was done through the same questionnaire, though adapted to a parent-report format (e.g., "I try to solve all of the 
problems of my son/daughter without him/her having to do anything"), using the same response scale (i.e., a 5-point Likert-type scale). The mother version had a good reliability as well $(\alpha=.90)$. Further, as recommended (De Los Reyes \& Ohannessian, 2016), measurement equivalence across mothers and adolescents was examined, in order to verify whether the questionnaire measures the same underlying construct across both informants. This was done through multi-group comparison, where the equivalence of a model with the five subscales as indicators of one latent factor was examined. Thereby, an unconstrained model (where factor loadings for the subscales are freely estimated) was compared with a constrained model (where loadings are set equal across the two groups; Vandenberg \& Lance, 2000). Evaluation of measurement equivalence was based on the difference in CFI ( $\triangle \mathrm{CFI})$, which should be lower than .010 (Cheung \& Rensvold, 2002). Analyses provided evidence for measurement equivalence $(\triangle \mathrm{CFI}=.005)$, indicating that the questionnaire measures the same underlying construct across adolescents and mothers.

Internalizing and externalizing problems. Adolescents completed the subscales assessing anxious/depressed problems (13 items) and withdrawn/depressed problems (8 items) of the Youth Self-Report (YSR; Achenbach \& Rescorla, 2001) to measure their internalizing problems, and they completed the YSR subscales assessing rule-breaking behavior (15 items) and aggressive behavior (10 items) to measure their externalizing problems. Items were rated on a scale from 0 ("Not at all") to 2 ("Very much"). Validation information about this frequently used scale is provided by, for instance, de Groot, Koot, and Verhulst (1996). In the present investigation, reliabilities were $\alpha=.88$ for internalizing problems and $\alpha=.80$ for externalizing problems.

Psychological need frustration. Adolescents reported upon their experiences of frustration (vs. satisfaction) in their need for autonomy, relatedness, and competence, through the 24-item Basic Psychological Need Satisfaction and Frustration Scale (BPNSFS; Chen et 
al., 2015). Specifically, eight items assessed the degree to which they generally experience a sense of pressure and coercion in their life, as opposed to a sense of autonomy, volition, and personal choice (e.g., "I feel forced to do many things I wouldn't choose to do"; "I feel a sense of choice and freedom in the things I undertake", reverse-coded). Eight items assessed their experiences of exclusion and isolation, as opposed to feelings of relatedness and genuine connectedness with important others (e.g., "I have the impression that people I spend time with dislike me"; "I feel that the people I care about also care about me", reverse-coded). Finally, eight items measured the degree to which adolescents feel like a failure in the things they undertake in life, as opposed to experiencing a sense of competence and effectiveness in their actions (e.g., "I feel like a failure because of the mistakes I make"; "I feel capable at what I do", reverse-coded). Adolescents rated items on a 5-point Likert-type scale, ranging from 1 (Completely untrue) to 5 (Completely true). This often-used scale has been shown to be valid across different age groups and across different cultures (e.g., Chen et al., 2015). In the present study, the separate subscales for the three needs were used, which were found to be reliable ( $\alpha=.78$ for autonomy; $\alpha=.84$ for relatedness; $\alpha=.84$ for competence).

\section{Data Analysis}

The data analysis followed the steps outlined by Barranti et al. (2017) and Shanock, Baran, Gentry, Pattison and Heggestad (2010), thereby making use of the RSA package (Version 0.9.13; Schönbrodt \& Humberg, 2018) in R 3.5.3 (R Development Core Team, 2016). A first step involved the provision of descriptive information about the occurrence of informant discrepancies. This is done by examining the frequency of observations where the adolescent scores of overprotection are higher than, equal to, or lower than the mother scores, with a difference exceeding half a standard deviation between the two scores being considered as indicative of a discrepancy between the two scores (cf. Shanock et al., 2010). In a next step, the adolescent reports and mother reports of overprotection were standardized, 
making use of pooled standard deviations across the two informants (cf. Weidmann, Schönbrodt, Ledermann \& Grob, 2017). By doing so, the two predictors have the same scale midpoint and are commensurate (i.e., they are measured on the same scale; Edwards, 2002), which is important for the interpretation of the results. Then, one polynomial regression analysis was conducted for each dependent variable, by regressing the outcome on the main effects of adolescent-reported and mother-reported overprotection, their squared terms (adolescent report ${ }^{2}$ and mother report ${ }^{2}$ ), and their interaction term (adolescent $\times$ mother report). These regression coefficients cannot be interpreted in isolation as in a common regression analysis (Barranti et al., 2017), but they are instead used to generate a response surface pattern, which is used to interpret the results from the polynomial regression analysis. This graphical representation depicts the three-dimensional relationship between the two predictor variables and the outcome variable, displaying all hypothetical values of the outcome variable at all possible combinations of the two predictor variables. This graphical representation also includes the line of congruence (i.e., where the values of the two predictor variables perfectly match) and the line of incongruence (i.e., where the values of one predictor are the opposite of the other predictor). Finally, on the basis of the results of each regression analysis, four coefficients were calculated $\left(a_{1}-a_{4}\right)$, which help interpret the response surface. Specifically, the first two coefficients evaluate statistically whether the slope of the line of congruence (LOC) is linear $\left(a_{1}\right)$, which would indicate a linear additive relationship between the two predictor variables and the outcome variable, or curvilinear $\left(a_{2}\right)$, which would indicate that there is curvilinearity in the relationship between the two predictor variables and the outcome variable. The other two coefficients evaluate whether the slope of the line of incongruence (LOIC) is linear $\left(a_{3}\right)$, which would indicate that there is a discrepancy effect on the outcome variable in one specific direction, or curvilinear $\left(a_{4}\right)$, which would indicate that there is a discrepancy effect on the outcome variable, regardless of the direction ${ }^{1}$. 


\section{Results}

\section{Preliminary Analyses}

Table 1 provides means, standard deviations, and correlations between the study variables. On average, adolescents reported higher levels of overprotective parenting as compared to their mothers $[t(401)=10.31, p<.001]$. Further, as for the occurrence of informant discrepancies, about $65 \%$ of the mother-adolescent dyads were found to have discrepant views about the degree to which mothers were overprotective. Specifically, $50.5 \%$ of the adolescents reported higher levels of overprotective parenting, $35.1 \%$ of the adolescents had relatively similar scores on parental overprotection as compared to their mothers (i.e., the difference between the standardized scores was less than half a standard deviation), whereas $14.4 \%$ of the adolescents reported lower levels of overprotective parenting than their mothers. This descriptive information indicates that there are a considerable number of observations with discrepant values, confirming that it makes practical sense to further investigate how congruence and incongruence in mother-reported and adolescent-reported overprotection are related to internalizing and externalizing problems and need frustration (Shanock et al., 2010). Further, unlike previous research (see Taber, 2010), neither adolescents' age nor their gender predicted informant discrepancies in parental overprotection.

Inspection of the correlations (Table 1) indicated a moderately positive relationship between adolescent-reported and mother-reported overprotection. Adolescent-reported overprotection related to higher levels of internalizing and externalizing problems, and higher levels of autonomy frustration, relatedness frustration, and competence frustration, whereas mother-reported overprotection was not significantly associated with any of the outcome variables. Finally, as previous research documented gender and age differences in some of our outcome variables (e.g., Bongers, Koot, van der Ende, \& Verhulst, 2003), five regression analyses were performed (one for each outcome variable), to examine the role of adolescents' 
gender and age. Gender and age were not significantly associated with adolescents' internalizing problems. However, gender related significantly to externalizing problems $(b=$ $.26, p<.001)$, with girls reporting less externalizing problems than boys. Age was not significantly associated with externalizing problems. In the prediction of autonomy frustration and relatedness frustration as well, there were gender differences $(b=-.12, p<.05$, for autonomy frustration; $b=-.12, p<.05$, for relatedness frustration), with girls scoring lower on both types of need frustration, and no age differences. Finally, both gender $(b=.15, p<$ $.01)$ and age $(b=.11, p<.05)$ were related significantly to competence frustration, with girls and older adolescents scoring higher on competence frustration. For these reasons, age and gender were controlled for throughout our main analyses. This was done by using residual scores of the dependent variables (thus partialling out the variance of gender and age) in the polynomial regression analyses.

\section{Main Analyses}

The results of the polynomial regression analyses and responses surface analyses are presented in Table 2, and are displayed graphically in Figures 2-6. In line with the guidelines of Shanock et al. (2010), the RSA coefficients (which are derived from the regression coefficients) were directly used to examine whether (in)congruence between adolescent reports and mother reports related to our outcome measures. The graphical visualization of our results further helped interpreting the findings. While plotting out the results, we followed the recommendation of depicting the raw data in the 3D-cube, as well as projecting a bagplot around these raw data points onto the response surface (Schönbrodt, 2016). The bagplot is a bivariate extension of the boxplot, depicting the position of the inner $50 \%$ of the points as well as the line separating outliers from inliers (Rousseeuw, Ruts, \& Tukey, 1999). When interpreting surface plots, one may be tempted to focus on the corners, as these are often most pronounced. However, these corners are usually extrapolations where no actual observations 
exist (Tufte, 2001). It is therefore recommended to refrain from interpreting regions that fall outside the bagplot, as they rely upon unlikely assumptions (Schönbrodt, 2016).

For adolescent internalizing problems (see Figure 2), evidence was obtained for a linear effect of the LOC (i.e., a significant $\mathrm{a}_{1}$ coefficient). This indicates that, when adolescents and mothers reported higher levels of overprotective parenting, adolescents were more likely to report higher levels of internalizing problems. The coefficients related to the LOIC were non-significant, indicating that there were no discrepancy effects for adolescent internalizing problems. For externalizing problems (see Figure 3), evidence for a linear effect of the LOC was obtained as well, indicating that higher levels of adolescent-reported and mother-reported overprotective parenting related to higher levels of adolescent externalizing problems. In addition, there was also a significant linear effect of the LOIC (i.e., a significant $a_{3}$ coefficient). This effect was positive, indicating that adolescents had more externalizing problems when adolescent reports of overprotection were higher than the mother reports.

Further, in the prediction of adolescent autonomy frustration (see Figure 4), neither the linear effect nor the curvilinear effect of the LOC reached statistical significance. However, the linear effect of the LOIC was significant and positive. This indicates that a discrepancy between mothers and adolescents relates to autonomy frustration, with adolescents reporting more autonomy frustration when they reported higher levels of overprotection than their mother (cf. the $a_{3}$ coefficient; see the right hand corner of Figure 4). As for adolescent relatedness frustration (see Figure 5), evidence for a linear effect of the LOC was obtained, indicating that higher levels of adolescent-reported and mother-reported overprotective parenting related to higher levels of relatedness frustration. In addition, there was also a significant linear effect of the LOIC, which indicates that adolescents experienced more relatedness frustration when their reports of overprotection were higher than their mothers'. Finally, for competence frustration (see Figure 6), the linear and curvilinear coefficients 
related to the LOC were significant. This finding indicates that higher levels of adolescentreported and mother-reported overprotective parenting are associated with more competence frustration. This association seems to flatten out at relatively higher levels of overprotective parenting (cf. the $\mathrm{a}_{2}$ coefficient and Figure 6). The linear and curvilinear coefficients of the LOIC were statistically not significant.

\section{Sensitivity Analyses and Alternate Model Analyses}

A first series of sensitivity analyses involved testing whether the statistical model is overfitted. Overfitting would imply that the model could be capitalized on the idiosyncratic characteristics of our specific sample (Harrell Jr., 2015). The statistical model would then describe random error, rather than the "true" relationships between variables. This problem could arise particularly in the case in complex statistical models, such as polynomial regression models. Overfitting of the model was examined through the use of the predicted $R^{2}$-statistic, which is an accelerated cross-validation method (Tarpey, 2000), relying upon the predicted error sum of squares (PRESS) statistic. This method first removes a data point from the dataset. Then, a refitted linear regression model is generated, which is then used to predict the value of the removed data point. This procedure is repeated for all data points. In the case of overfitting, these predicted values are likely to strongly diverge from the observed values, which would be reflected in a low or negative predicted $R^{2}$-value. For internalizing and externalizing problems and autonomy frustration, these analyses do not suggest a problem of overfitting, as the predicted $R^{2}$-values varied between .04 and .07 , whereas the adjusted $R^{2}$ values ranged between .08 and .12. For relatedness frustration and competence frustration, however, $R^{2}$-values were rather low, with an adjusted $R^{2}$-value of .03 and a predicted $R^{2}$-value of .01 for both dependent variables. This indicates that the results for relatedness frustration and competence frustration should be interpreted with some caution, warranting further replication. 
Further, in order to gain a more fine-grained understanding of our results, all polynomial regression analyses were repeated five times, using each of the subscales of the overprotection scale separately. The overall pattern clearly converged with the overall findings using the total score, yet certain subscales were more strongly linked to certain outcome variables. The Premature Problem-Solving subscale yielded the strongest similarities with the overall results, being associated with each of the outcome variables. That is, there was evidence for linear effects along the LOC for internalizing problems, relatedness frustration, and competence frustration, as well as linear effects along the LOIC for externalizing problems, autonomy frustration and relatedness frustration (as was the case with the overall score). Results for the Infantilization subscale and the Privacy Invasion subscale were consistent with the overall results for externalizing problems and for the frustration each of the three needs. Only the association with internalizing problems turned out to be nonsignificant. Finally, as for the Anxious Rearing subscale and the General Overprotection subscale, results were similar for internalizing problems (i.e., a linear effect of the LOC) and for autonomy frustration (i.e., a curvilinear effect of the LOIC). Associations with externalizing problems, relatedness frustration and competence frustration were generally non-significant.

Finally, a path model involving mediation was tested. This model assumes that autonomy frustration explains the linear effect of incongruence in mother-reported vs. adolescent-reported overprotection on adolescent externalizing problems (see also Comment 2 of Reviewer 2). This model was tested because the linear effect of incongruence was related to both autonomy frustration and externalizing problems, and as previous research suggests that autonomy frustration may be especially relevant in the context of adolescent externalizing problems (e.g., Van Petegem, Vansteenkiste, Soenens, Beyers, \& Aelterman, 2015b). However, there is no previous research testing the intervening role of autonomy frustration in 
the association between parental overprotection and externalizing problems (see Schiffrin et al., 2019, for research on the link with internalizing problems). A path analysis (based on maximum likelihood estimation with 5.000 bootstrap samples; Cerin \& MacKinnon, 2008) indicated that incongruence was predictive of autonomy frustration $(a=.26,95 \% \mathrm{CI}[.13$, $.39])$, which in turn predicted more externalizing problems $(b=.09,95 \%$ CI $[.04, .14])$. Both the direct effect of incongruence on externalizing problems was significant $\left(c^{\prime}=.07,95 \% \mathrm{CI}\right.$ $[.02, .12])$, as well as the indirect effect through autonomy frustration $(a b=.02,95 \% \mathrm{CI}[.01$, $.05])$, yielding a total effect of $c=.09,95 \%$ CI $[.04, .15]$. Taken together, these analyses suggest that autonomy frustration partially explains the linear effect of incongruence in mother-reported vs. adolescent-reported overprotection on externalizing problems.

\section{Discussion}

Overprotective parenting involves parents' provision of protection that is excessive, when taking into consideration the adolescents' developmental status (Thomasgard et al., 1995). In other words, by its very definition, parental overprotection implies a mismatch between parents' involvement and adolescents' developmental needs. Therefore, it is important to examine discrepancies between parents' and adolescents' views on overprotective parenting, and with particular attention to the situation where adolescents perceive more overprotection than reported by their parents. Accordingly, the present multiinformant study examined whether convergence and divergence in adolescents' vs. mothers' reports of overprotective parenting related to adolescents' internalizing and externalizing problems and their psychological need frustration.

The results not only replicated previous research about the maladaptive correlates of overprotective parenting (e.g., Schiffrin et al., 2014), but also highlighted the importance of considering parents' and adolescents' differential perceptions of parental overprotection, because for three out of five outcome variables, discrepancies in adolescents' vs. mothers' 
reports significantly related to adolescent maladjustment. Thus, although adolescents' perceptions of the parents' behaviors are typically stronger predictors of their adjustment than parents' reports (e.g., Hendriks et al, 2018), the current results indicate that it is important not only to consider separate effects of adolescent and parent reports. Instead, the combination of both type of reports, and in particular their congruence or incongruence, yields additional information and predictive value: a consideration of mothers' perspective (and its discrepancy with adolescents' point of view) helped explaining why some adolescents exhibit more externalizing problems and feel frustrated in their psychological needs. Such important discrepancy effects would have gone unnoticed if only a single perspective or informant would have been used (see also De Los Reyes, 2011).

\section{Associations of Congruence and Incongruence in Reports of Overprotective Parenting}

Previous research has shown rather consistently that, during adolescence and young adulthood, overprotective parenting is associated with internalizing problems, including anxiety and depressive symptoms (e.g., Spada et al., 2012) and functional somatic symptoms (e.g., Janssens, Oldehinkel, \& Rosmalen, 2009). The present results confirm these findings, as adolescents reported higher levels of internalizing problems when scores on adolescentreported and mother-reported overprotection were high. No evidence was found for effects of incongruence, however, indicating that adolescents' vs. mothers' discrepant perceptions of overprotection did not explain any additional variance in adolescents' internalizing problems.

Fewer studies focused on the association between overprotective parenting and adolescent externalizing problems (but see e.g., Nishikawa, Sundbom, \& Hägglöf, 2010). In our study, evidence was found for a congruence effect of overprotective parenting as well as an effect of incongruence in adolescent-reported vs. mother-reported overprotection. That is, in families where adolescents and mothers reported high levels of parental overprotection, adolescents were more likely to report more externalizing problems. Importantly, evidence for 
a discrepancy effect was also obtained. Specifically, when adolescents perceived more overprotection than what was reported by their mothers, they tended to report higher levels of externalizing problems as well. Such findings are in line with previous work, showing that more negativity in adolescents' perceptions (as compared to parents' perceptions) of the family climate represents a risk for maladjustment (e.g., Human et al., 2016). In the specific case of overprotective parenting, this discrepancy may reflect a pattern where mothers believe that their involvement is attuned to the adolescents' needs; however, adolescents do not experience their mother's involvement as such, but rather as intrusive and meddlesome. Potentially, such experiences of intrusive parenting may then trigger feelings of reactance among adolescents, that is, a tendency to reject authority and to do the opposite of what is expected (Brehm, 1966), which may in turn motivate adolescents to engage in oppositional and rule-breaking behavior (Van Petegem, Soenens, Vansteenkiste, \& Beyers, 2015a). In line with this, previous longitudinal research among adolescents found that controlling parenting predicted more reactance across time, in turn predicting increases in destructive conflict engagement strategies within the family (Missotten, Luyckx, Branje, \& Van Petegem, 2018).

This interpretation is further corroborated by the findings regarding the association with autonomy frustration, which parallel the findings regarding externalizing problems. Specifically, there was a linear effect along the line of incongruence, which indicated higher scores for autonomy frustration when adolescents experienced more overprotection than what mothers reported. In other words, when parents' involvement is experienced as excessive and not attuned to adolescents' needs, adolescents are more likely to experience pressure and coercion in their daily life, thereby feeling like they have to act in ways imposed by other people, rather than in ways congruent with their personal values and interests (Van Petegem, Vansteenkiste, \& Beyers, 2013). This may, in turn, predict feelings of reactance and a tendency to engage in externalizing behavior. In line with this interpretation, previous 
research among adolescents found that intrusive parenting was predictive of autonomy frustration and feelings of being overly controlled, which in turn was related to more oppositional and rule-breaking behavior (e.g., Kakihara, Tilton-Weaver, Kerr, \& Stattin, 2010; Van Petegem et al., 2017). In other words, autonomy frustration might be an explaining mechanism for the association between congruence and incongruence in reports of overprotective parenting and adolescent externalizing symptoms. The alternate model analyses provided partial support for this interpretation, although future research would be needed to test this hypothesis more in-depth.

Further, for relatedness frustration, there were linear effects for both congruence and incongruence in adolescents' and mothers' reports of overprotective parenting. Thus, when both adolescents and mothers reported higher levels of overprotective parenting, adolescents were more likely to feel frustrated in their need for relatedness. Thus, even though overprotective parents often have the well-intended goal of shielding away their child from potentially emotionally arousing situations by being highly affectionate and by displaying warmth and care (Padilla-Walker \& Nelson, 2012), adolescents do not necessarily experience these practices as truly supportive. This interpretation is further confirmed by the linear effect along the line of incongruence: when adolescents' reports exceed mothers' reports, adolescents especially seem to experience relatedness frustration. Thus, involvement that is out of tune with the adolescents' developmental needs seems to be especially harmful for adolescents' sense of relatedness in important relationships. This finding is in line with previous work showing that overprotective parenting is associated with less open and more problematic family communication patterns (Segrin et al., 2012) and with research suggesting that overprotective parenting has a cost for adolescents' peer relationships as well (van Ingen et al., 2015). 
Finally, for competence frustration, there was evidence for effects along the line of congruence, indicating higher levels of competence frustration when adolescents and mothers report more overprotective parenting. These findings generally converge with previous research, mostly among university students, suggesting that overprotective parenting is associated with lower levels of self-efficacy (e.g., Reed, Duncan, Lucier-Greer, Fixelle, \& Ferraro, 2016), maladaptive coping strategies (e.g., Segrin et al., 2013), and lower academic achievement (Schiffrin \& Liss, 2017). Although parental overprotection may result from parents' desire to help their children facing challenges and difficulties effectively, these results suggests that these parental efforts may backfire. That is, overprotective parents limit adolescents' opportunities for practicing and developing coping skills, and as a consequence, adolescents seem to be more likely to feel ineffective in coping with failures and difficulties (cf. Rubin, Burgess, \& Hastings, 2002). Of course, this process is likely transactional, as parents are also likely to respond to children's failure and lack of competence by becoming overly involved and more intrusive (Grolnick, Gurland, DeCourcey, \& Jacob, 2002;

Robichaud, Bureau, Ranger, \& Mageau, 2019). To test such hypotheses, longitudinal research is needed.

\section{Practical Implications}

The present findings have important practical implications. Western societies put a lot of pressure on parents (and on mothers in particular), prescribing how "good parents" ought to raise their children (e.g., Hays, 1996; Newman \& Henderson, 2014). As parents are confronted with a culture that is aversive to risk and danger (Furedi, 2008; Lee, Bristow, Faircloth, \& Macvarish, 2014), parents may feel pressured to shield their children away from danger (Gurland \& Grolnick, 2005; Lukianoff \& Haidt, 2018). In addition, parents’ overinvolvement may be fueled further by recent socio-economic changes, including increases in job insecurity and unemployment (Mintz, 2017). However, as the present study shows, such 
well-intentioned parenting practices may backfire, as they seem to hamper adolescents' wellbeing. Therefore, as children move into adolescence, it is important for parents to adjust their level of protection and involvement to meet the developmental needs of their developing adolescent, including their increasing need for independence (Gutmann \& Eccles, 2007). In that respect, researchers especially underscore the importance of autonomy-supportive parenting as a positive alternative for overprotective parenting (Clark, Cooper, \& Creswell, 2013). Autonomy-supportive parenting involves being empathic and sensitive for the adolescents' perspective, encouraging initiative, and offering choice whenever possible (Grolnick, 2003), and has been shown to foster adolescents' optimal development (for a review, see e.g., Joussemet, Landry \& Koestner, 2008). There is emerging evidence that autonomy-supportive parenting can be taught to parents, either through group sessions (Joussemet, Mageau, \& Koestner, 2014) or through individual counseling (Allen, Grolnick, \& Cordova, 2019), with ensuing benefits for children's development. Importantly, however, while working with parents, professionals should be mindful about the larger societal, historical, economical and political context in which parent-child interactions take place (Bronfenbrenner, 1979; Corsaro, 2011; Doepke \& Zilibotti, 2019), in order to avoid the rhetoric of "parent-blaming", which often is an implicit message of parenting advice (Bristow, 2014; Garey \& Arendell, 2001).

Also, our findings suggest that parenting programs focusing on autonomy-relevant themes would do well integrating the consideration of informant discrepancies (cf. De Los Reyes, 2013), for instance through discussions of how parents and adolescents view certain parental behaviors differently. By doing so, parents and adolescents could be made aware of the fact that they might hold different perspectives on certain parental behaviors. Such knowledge may be insightful for parents, who may come to realize that their (often wellintended) actions could be experienced differently, and do not necessarily meet their 
adolescent's needs. At the same time, by discussing these discrepant views on parenting behaviors, adolescents may come to better understand their parents' intentions, such that they develop a more benign understanding of their parents' involvement. As the present study suggests, becoming better aware and more attuned to each other's needs may have positive implications for adolescents' optimal development.

\section{Limitations and Future Research}

This study has a number of shortcomings. First, it is based upon cross-sectional data, so no inferences can be made about directionality of effects. The dynamics involved in overprotective parenting are most likely to be transactional: parental overinvolvement is likely to not only give rise to difficulties in children, but also is often a response to children's behaviour or temperamental factors (e.g., Rapee, 1997). Thus, parental overprotection is likely to reinforce and exacerbate psychosocial difficulties among children and adolescents. Similarly, discrepant views about parental overprotection may also develop across time and may be a result of child difficulties as well. For instance, adolescents displaying more externalizing problems may increasingly interpret any parental behaviour as intrusive and meddlesome (cf. Dodge, 2006); in this case, externalizing problems would predict increases in discrepant views about parental overprotection across time. Longitudinal research is needed to test such hypotheses explicitly.

In addition, the present study only drew upon adolescent reports of their internalizing and externalizing problems. Although children and adolescents are generally more capable of accurately reporting upon their own experiences and emotions, as compared to other reporters (e.g., Walden, Harris, \& Catron, 2003), it may be interesting for future research to include other informants with regards to their internalizing and externalizing problems as well. For instance, it could very well be the case that discrepancies in adolescent reports vs. parent reports of adolescents' externalizing problems (with parent reports exceeding adolescent 
reports) are linked to discrepancies in reports of overprotective parenting (with adolescent reports exceeding parent reports). A full multi-informant design is needed to test such hypotheses.

Another limitation involves the sole focus upon maternal overprotection, excluding adolescents' perceptions of paternal overprotection and fathers' own reports of overprotective parenting. Although parental overprotection traditionally has been portrayed primarily as a maternal phenomenon (e.g., Levy, 1943), there have been important changes in paternal involvement across the last decades (e.g., Hall, 2005). Nevertheless, most research on overprotective parenting has focused on maternal overprotection, excluding fathers' point of view (Brussoni \& Olsen, 2012). This is unfortunate, as this one-sided focus on mothers may implicitly reinforce societal representations of mothers being the primary socialization figure (Wall \& Arnold, 2007). Therefore, it is of crucial importance for future research to also focus on fathers' overprotective parenting and to include their perspectives as well.

\section{Conclusion}

Although a growing body of research indicates that overprotective parenting is linked to maladjustment in adolescence and young adulthood, only few studies make use of a multiinformant design to tackle this question. This is unfortunate as overprotective parenting, by its very definition, implies a discrepancy between what parents provide (in terms of protection) and what children need developmentally (Holmbeck et al., 2002), hence necessitating a multiinformant design. The present multi-informant investigation corroborates previous research by showing that maternal overprotective parenting was associated with more internalizing and externalizing problems and with frustration of adolescents' psychological need for relatedness and competence. In addition, it extends our understanding of the phenomenon of overprotective parenting by showing that overprotective parenting may be particularly harmful when mothers and adolescents diverge in their perceptions of overprotective 
parenting. Specifically, when adolescents experienced higher levels of overprotective parenting than what was reported by their mothers, they were especially more likely to report higher levels of externalizing problems, and to feel frustrated in their needs for autonomy and relatedness. Overall, these findings underscore the importance of using a multi-informant approach to the assessment of overprotective parenting and indicate that Response Surface Analysis is a promising statistical tool to analyse such multi-informant data in depth. 


\section{Footnotes}

${ }^{1}$ The RSA coefficients are calculated on the basis of the unstandardized polynomial regression coefficients: $a_{1}=b_{1}+b_{2} ; a_{2}=b_{3}+b_{4}+b_{5} ; a_{3}=b_{1}-b_{2} ; a_{4}=b_{3}-b_{4}+b_{5}$. 


\section{References}

Achenbach, T. M., \& Rescorla, L. A. (2001). Manual for ASEBA school-age forms \& profiles. Burlington, VT: Research Centre for Children, Youth \& Families.

Allen, E. S., Grolnick, W. S., \& Córdova, J. V. (2019). Evaluating a self-determination theory-based preventive parenting consultation: The parent check-in. Journal of Child and Family Studies, 28, 732-743.

Barger, M. M., Kim, E. M., Kuncel, N. R., \& Pomerantz, E. M. (2019). The relation between parents' involvement in children's schooling and children's adjustment: A metaanalysis. Psychological Bulletin, 145, 855-890.

Barranti, M., Carlson, E. N. \& Côté, S. (2017). How to test questions about similarity in personality and social psychology research: Description and empirical demonstration of response surface analysis. Social Psychological and Personality Science, 8, 465475.

Bongers, I. L., Koot, H. M., van der Ende, J., \& Verhulst, F. C. (2003). The normative development of child and adolescent problem behavior. Journal of Abnormal Psychology, 112, 179-192.

Bradley-Geist, J. C., \& Olson-Buchanan, J. B. (2014). Helicopter parents: An examination of the correlates of over-parenting of college students. Education + Training, 56, 314328.

Brehm, J. W. (1966). A theory of psychological reactance. Oxford, England: Academic Press.

Brenning, K., Soenens, B., Van Petegem, S. \& Kins, E. (2017). Searching for the roots of overprotective parenting in emerging adulthood: Investigating the link with parental attachment representations using an Actor Partner Interdependence Model (APIM). Journal of Child and Family Studies, 26, 2299-2310. 
Bristow, J. (2014). The double bind of parenting culture: Helicopter parents and cotton wool kids. In E. Lee, J. Bristow, C. Faircloth, \& J. Macvarish (Eds.), Parenting culture studies (pp. 200-215). London, UK: Palgrave Macmillan.

Bronfenbrenner, U. (1979). The ecology of human development: Experiments by nature and design. Cambridge: Harvard University Press.

Brussoni, M., \& Olsen, L. L. (2013). The perils of overprotective parenting: Fathers' perspectives explored. Child: Care, Health and Development, 39, 237-245.

Cerin, E., \& MacKinnon, D. P. (2008). A commentary on current practice in mediating variable analyses in behavioural nutrition and physical activity. Public Health Nutrition, 12, 1182-1188.

Chen, B., Vansteenkiste, M., Beyers, W., Boone, L., Deci, E. L., Van der Kaap-Deeder, J., ..., \& Verstuyf, J. (2015). Basic psychological need satisfaction, need frustration, and need strength across four cultures. Motivation and Emotion, 39, 216236.

Cheung, G. W., \& Rensvold, R. B. (2002). Evaluating goodness-of-fit indexes for testing measurement invariance. Structural Equation Modeling, 9, 233-255.

Clarke, K. \& Cooper, P., \& Creswell, C. (2013). The Parental Overprotection Scale: Associations with child and parental anxiety. Journal of Affective Disorders, 151, 618624.

Corsaro, W. A. (2011). The sociology of childhood ( $3^{\text {rd }}$ edition). Thousand Oaks, CA: Pine Forge Press.

de Groot, A., Koot, H. M., \& Verhulst, F. C. (1996). Cross-cultural generalizability of the Youth Self-Report and Teacher's Report Form cross-informant syndromes. Journal of Abnormal Child Psychology, 24, 651-664. 
de Haan, A., Prinzie, P., Sentse, M., \& Jongerling, J. (2018). Latent difference score modeling: A flexible approach for studying informant discrepancies. Psychological Assessment, 30, 358-369.

De Los Reyes, A. (2011). Introduction to the special section: More than measurement error: Discovering meaning behind informant discrepancies in clinical assessments of children and adolescents. Journal of Clinical Child and Adolescent Psychology, 40, 19.

De Los Reyes, A. (2013). Strategic objectives for improving understanding of informant discrepancies in developmental psychopathology research. Development and Psychopathology, 25, 669-682.

De Los Reyes, A., Goodman, K. L., Kliewer, W. \& Reid-Quiñones, K. (2010). The longitudinal consistency of mother-child reporting discrepancies of parental monitoring and their ability to predict child delinquent behaviors two years later. Journal of Youth and Adolescence, 39, 1417-1430.

De Los Reyes, A., \& Ohannessian, C. M. (2016). Introduction to the special issue: Discrepancies in adolescent-parent perceptions of the family and adolescent adjustment. Journal of Youth and Adolescence, 45, 1957-1972.

De Los Reyes, A., Ohannessian, C. M., \& Laird, R. D. (2016). Developmental changes in discrepancies between adolescents' and their mothers' views of family communication. Journal of Child and Family Studies, 25, 790-797.

Dodge, K. A. (2006). Translational science in action: Hostile attributional style and the development of aggressive behavior problems. Development and Psychopathology, $18,791-814$.

Doepke, M., \& Zilibotti, F. (2019). Love, money and parenting: How economics explains the way we rise our kids. Princeton, NJ: Princeton University Press. 
Edwards, J.R. (2002). Alternatives to difference scores: Polynomial regression analysis and response surface methodology. In F. Drasgow \& N. W. Schmitt (Eds.), Advances in measurement and data analysis (pp. 350-400). San Francisco: Jossey-Bass.

Furedi, F. (2008). Paranoid parenting: Abandon your anxieties and be a good parent. New York, NY: Continuum.

Garey, A. I., \& Arendell, T. (2001). Children, work, and family: Some thoughts on 'mother blame'. In R. Hertz and N. Marshall (Eds.), Working families: The transformation of the American home. Berkeley, CA: University of California Press.

Grolnick, W. S. (2003). The psychology of parental control: How well-meant parenting backfires. Mahwah, NJ: Erlbaum.

Grolnick, W. S., Gurland, S. T., DeCourcey, W., \& Jacob, K. (2002). Antecedents and consequences of mothers' autonomy support: An experimental investigation. Developmental Psychology, 38, 143-155.

Grüner, K., Muris, P., \& Merckelbach, H. (1999). The relationship between anxious rearing behaviours and anxiety disorders symptomatology in normal children. Journal of Behavior Therapy and Experimental Psychiatry, 30, 27-35.

Grusec, J.E. \& Davidov, M. (2010). Integrating different perspectives on socialization theory and research: A domain-specific approach. Child Development, 8, 687-709.

Gurland, S. T., \& Grolnick, W. S. (2005). Perceived threat, controlling parenting, and children's achievement orientations. Motivation and Emotion, 29, 103-121.

Gutman, L. M., \& Eccles, J. S. (2007). Stage-environment fit during adolescence: Trajectories of family relations and adolescent outcomes. Developmental Psychology, 43, 522-537.

Hall, S. S. (2005). Change in paternal involvement from 1977 to 1997: A cohort analysis. Family and Consumer Sciences Research Journal, 34, 127-139. 
Harrell Jr., F. E. (2015). Regression modelling strategies: With applications to linear models, logistic regression, and survival analysis. New York, NY: Springer.

Hawk, S. T., Keijsers, L., Hale III, W. W. \& Meeus, W. (2009). Mind your own business! Longitudinal relations between perceived privacy invasion and adolescent-parent conflict. Journal of Family Psychology, 23, 511-520.

Hendriks, A. M., Van der Giessen, D., Stams, G. J. J. M., \& Overbeek, G. (2018). The association between parent-reported and observed parenting: A multi-level metaanalysis. Psychological Assessment, 30, 621-633.

Holmbeck, G. N., Johnson, S. Z., Wills, K. E., McKernon, W., Rose, B., Erklin, S. \& Kemper, T. (2002). Observed and perceived parental overprotection in relation to psychosocial adjustment in preadolescents with a physical disability: The mediational role of behavioral autonomy. Journal of Consulting and Clinical Psychology, 70, 96110.

Hudson, J. \& Rapee, R. (2001). Parent-child interactions and anxiety disorders: An observational study. Behaviour Research and Therapy, 39, 1411-1427.

Human, L. J., Dirks, M. A., DeLongis, A., \& Chen, E. (2016). Congruence and incongruence in adolescents' and parents' perceptions of the family: Using response surface analysis to examine links with adolescents' psychological adjustment. Journal of Youth and Adolescence, 45, 2022-2035.

Janssens, K. A., Oldehinkel, A. J., \& Rosmalen, J. G. (2009). Parental overprotection predicts the development of functional somatic symptoms in young adolescents. The Journal of Pediatrics, 154, 918-923.

Joussemet, M., Landry, R., \& Koestner, R. (2008). A self-determination theory perspective on parenting. Canadian Psychology, 49, 194-200. 
Joussemet, M., Mageau, G. A., \& Koestner, R. (2014). Promoting optimal parenting and children's mental health: A preliminary evaluation of the how-to parenting program. Journal of Child and Family Studies, 23, 949-964.

Kakihara, F., Tilton-Weaver, L., Kerr, M., \& Stattin, H. (2010). The relationship of parental control to youth adjustment: Do youths' feelings about their parents play a role? Journal of Youth and Adolescence, 39, 1442-1456.

Kins, E., \& Soenens, B. (2013). Generation me and its helicopter parents. Paper presented at the 16th European Conference on Developmental Psychology, Lausanne, Switzerland.

Korelitz, K. E., \& Garber, J. (2016). Congruence of parents' and children’s perceptions of parenting: A meta-analysis. Journal of Youth and Adolescence, 45, 1973-1995.

Laird, R. D., \& De Los Reyes, A. (2013). Testing informant discrepancies as predictors of early adolescent psychopathology: Why difference scores cannot tell you what you want to know and how polynomial regression may. Journal of Abnormal Child Psychology, 41, 1-14.

Lee, E., Bristow, J., Faircloth, C. \& Macvarish, J. (2014) Parenting culture studies. Basingstoke and New York: Palgrave Macmillan.

LeMoyne, T. \& Buchanan, T. (2011). Does "hovering" matter? Helicopter parenting and its effect on well-being. Sociological Spectrum, 31, 399-418.

Levy, D. M. (1943). Maternal overprotection. New York, NY: Columbia University Press. Lukianoff, G., \& Haidt, J. (2018). The coddling of the American mind: How good intentions and bad ideas are setting up a generation for failure. Penguin Press.

Mintz, S. (2017). Why history matters: Placing infant and child development in historical perspective. European Journal of Developmental Psychology, 14, 647-658. 
Missotten, L. C., Luyckx, K., Branje, S., \& Van Petegem, S. (2018). Adolescents' conflict management styles with mothers: Longitudinal associations with parenting and reactance. Journal of Youth and Adolescence, 47, 260-274.

Muris, P., Meesters, C. \& van den Berg, F. (2003). The Strengths and Difficulties Questionnaire (SDQ): Further evidence for its reliability and validity in a community sample of Dutch children and adolescents. European Child \& Adolescent psychiatry, $12,1-8$.

Nishikawa, S., Sundbom, E., \& Hägglöf, B. (2010). Influence of perceived parental rearing on adolescent self-concept and internalizing and externalizing problems in Japan. Journal of Child and Family Studies, 19, 57-66.

Ohannessian, C. M. (2012). Parental problem drinking and adolescent psychosocial adjustment: The mediating role of adolescent-parent communication. Journal of Research on Adolescence, 22, 498-511.

Ohannessian, C. M., \& De Los Reyes, A. (2014). Discrepancies in adolescents' and their mothers' perceptions of the family and adolescent anxiety symptomatology. Parenting, 14, 1-18.

Padilla-Walker, L. M., \& Nelson, L. J. (2012). Black hawk down?: Establishing helicopter parenting as a distinct construct from other forms of parental control during emerging adulthood. Journal of Adolescence, 35, 1177-1190.

Parker, G. (1983). Parental overprotection: A risk factor for psychosocial development. New York: Grune and Stratton.

R Development Core Team. (2016). R: A language and environment for statistical computing. Vienna, Austria: R Foundation for Statistical Computing.

Rapee, R. M. (1997). Potential role of childrearing practices in the development of anxiety and depression. Clinical Psychology Review, 17, 47-67. 
Reed, K., Duncan, J. M., Lucier-Greer, M., Fixelle, C., \& Ferraro, A. J. (2016). Helicopter parenting and emerging adult self-efficacy: Implications for mental and physical health. Journal of Child and Family Studies, 25, 3136-3149.

Robichaud, J. M., Bureau, J. S., Ranger, F., \& Mageau, G. A. (2019). The relation between children's task-specific competence and mothers' controlling practices. Social Development, 28, 120-135.

Roelofs, J., Meesters, C., ter Huurne, M., Bamelis, L. \& Muris, P. (2006) On the links between attachment style, parental rearing behaviors, and internalizing and externalizing problems in non-clinical children. Journal of Child and Family Studies. $15,319-332$.

Rote, W. M., \& Smetana, J. G. (2016). Patterns and predictors of mother-adolescent discrepancies across family constructs. Journal of Youth and Adolescence, 45, 20642079.

Rousseau, S. \& Scharf, M. (2015). "I will guide you”: the indirect link between overparenting and young adults' adjustment. Psychiatry Research, 228, 826-834.

Rousseeuw, P. J., Ruts, I., \& Tukey, J. W. (1999). The bagplot: A bivariate boxplot. The American Statistician, 53, 382-387.

Rubin, K. H., Burgess, K. B., \& Hastings, P. D. (2002). Stability and social-behavioral consequences of toddlers' inhibited temperament and parenting behaviors. Child Development, 73, 483-495.

Ryan, R. M. \& Deci, E. L. (2000). Self-determination theory and the facilitation of intrinsic motivation, social development, and well-being. American Psychologist, 55, 68-78.

Ryan, R. M. \& Deci, E. L. (2017). Self-determination theory: Basic psychological needs in motivation, development, and wellness. New York, NY: Guilford Press. 
Ryan, R. M., Deci, E. L. \& Vansteenkiste, M. (2016). Autonomy and autonomy disturbances in self-development and psychopathology: Research on motivation, attachment, and clinical process. In D. Cichetti (Ed.), Developmental psychopathology (3rd ed., pp. 154). New York, NY, US: Wiley.

Schiffrin, H. H., \& Liss, M. (2017). The effects of helicopter parenting on academic motivation. Journal of Child and Family Studies, 26, 1472-1480.

Schiffrin, H. H., Liss, M., Miles-McLean, H., Geary K. A., Erchull M. J., \& Tashner, T. (2014). Helping or hovering? The effects of helicopter parenting on college students' well-being. Journal of Child and Family Studies, 23, 548-557.

Schiffrin, H. H, Erchull, M. \& Sendrick, E., Yost, J. C., Power, V., \& Saldanha, E. R. (2019). The effects of maternal and paternal helicopter parenting on the self-determination and well-being of emerging adults. Journal of Child and Family Studies. Advance online publication. doi: 0.1007/s10826-019-01513-6

Schönbrodt, F. D. (2018). Testing fit patterns with polynomial regression models.

\section{Unpublished manuscript.}

Schönbrodt, F. D., \& Humberg, S. (2018). RSA: An R package forresponse surface analysis (version 0.9.12). Retrieved from https://CRAN.R-pro-ject.org/package=RSA.

Schönbrodt, F. D., Humberg, S., \& Nestler, S. (2018). Testing similarity effects with dyadic response surface analysis. European Journal of Personality, 32, 627-641.

Segrin, C. G., Givertz, M., Swaitkowski, P. \& Montgomery, N. (2015). Overparenting is associated with child problems and a critical family environment. Journal of Child and Family Studies, 24, 470-479.

Segrin, C., Woszidlo, A., Givertz, M., Bauer, A., \& Murphy, M. T. (2012). The association between overparenting, parent-child communication, and entitlement and adaptive traits in adult children. Family Relations, 61, 237-252. 
Segrin, C., Woszidlo, A., Givertz, M., \& Montgomery, N. (2013). Parent and child traits associated with overparenting. Journal of Social and Clinical Psychology, 32, 569595.

Shanock, L. R., Baran, B. E., Gentry, W. A., Pattison, S. C., \& Heggestad, E. D. (2010). Polynomial regression with response surface analysis: A powerful approach for examining moderation and overcoming limitations of difference scores. Journal of Business and Psychology, 25, 543-554.

Smetana, J., Campione-Barr, N. \& Metzger, A. (2006). Adolescent development in interpersonal and societal contexts. Annual Review of Psychology, 57, 255-284.

Smetana, J., Crean, H. F., \& Campione-Barr, N. (2005). Adolescents' and parents' changing conceptions of parental authority. New Directions for Child and Adolescent Development, 108, 31-46.

Soenens, B., Vansteenkiste, M., \& Luyten, P. (2010). Toward a domain-specific approach to the study of parental psychological control: Distinguishing between dependencyoriented and achievement-oriented psychological control. Journal of Personality, 78, 217-256.

Spada, M. M., Caselli, G., Manfredi, C., Rebecchi, D., Rovetto, F., Ruggiero, G. M., ... \& Sassaroli, S. (2012). Parental overprotection and metacognitions as predictors of worry and anxiety. Behavioural and Cognitive Psychotherapy, 40, 287-296..

Taber, S. M. (2010). The veridicality of children's reports of parenting: A review of factors contributing to parent-child discrepancies. Clinical Psychology Review, 30, 999-1010.

Tarpey, T. (2000). A note on the prediction sum of squares statistic for restricted least squares. The American Statistician, 54, 116-118. 
Thomasgard, M., Metz, W. P., Edelbrock, C. \& Shonkoff, J. P. (1995). Parent-child relationship disorders: I. Parental overprotection and the development of the Parent Protection Scale. Journal of Developmental and Behavioral Pediatrics, 16, 244-250.

Tufte, E. R. (2001). The visual display of quantitative information. Cheshire, CT: Graphics press.

Vandenberg, R. J., \& Lance, C. E. (2000). A review and synthesis of the measurement invariance literature: Suggestions, practices, and recommendations for organizational research. Organizational Research Methods, 3, 4-70.

van Ingen, D. J., Freiheit, S. R., Steinfeldt, J. A., Moore, L. L., Wimer, D. J., Knutt, A. D., ... \& Roberts, A. (2015). Helicopter parenting: The effect of an overbearing caregiving style on peer attachment and self-efficacy. Journal of College Counseling, 18, 7-20.

Van Petegem, S., Soenens, B., Vansteenkiste, M., \& Beyers, W. (2015a). Rebels with a cause? Adolescent defiance from the perspective of reactance theory and selfdetermination theory. Child Development, 86, 903-918.

Van Petegem, S., Vansteenkiste, M., \& Beyers, W. (2013). The jingle-jangle fallacy in adolescent autonomy in the family: In search of an underlying structure. Journal of Youth and Adolescence, 42, 994-1014.

Van Petegem, S., Vansteenkiste, M., Soenens, B., Beyers, W., \& Aelterman, N. (2015b). Examining the longitudinal association between oppositional defiance and autonomy in adolescence. Developmental Psychology, 51, 67-74.

Van Petegem, S., Zimmer-Gembeck, M. J., Soenens, B., Vansteenkiste, M., Brenning, K., Mabbe, E., Vanhalst, J., \& Zimmermann, G. (2017). Does general parenting context modify adolescents' appraisals and coping with a situation of parental regulation? The case of autonomy-supportive parenting. Journal of Child and Family Studies, 26, 2623-2639. 
Walden, T. A., Harris, V. S., \& Catron, T. F. (2003). How I feel: A self-report measure of emotional arousal and regulation for children. Psychological Assessment, 15, 399-412.

Wall, G., \& Arnold, S. (2007). How involved is involved fathering? An exploration of the contemporary culture of fatherhood. Gender \& Society, 21, 508-527.

Weidmann, R., Schönbrodt, F. D., Ledermann, T., \& Grob, A. (2017). Concurrent and longitudinal dyadic polynomial regression analyses of Big Five traits and relationship satisfaction: Does similarity matter? Journal of Research in Personality, 70, 6-15. 
Table 1. Means, Standard Deviations and Correlations among the Study Variables

\begin{tabular}{|c|c|c|c|c|c|c|c|c|}
\hline & Mean & $S D$ & 1. & 2. & 3. & 4. & 5. & 6. \\
\hline 1. Adolescent-reported overprotection & 2.45 & .53 & & & & & & \\
\hline 2. Mother-reported overprotection & 2.17 & .44 & $.35^{* *}$ & & & & & \\
\hline 3. Internalizing problems & 0.51 & .33 & $.30 * *$ & .12 & & & & \\
\hline 4. Externalizing problems & 0.23 & .19 & $.33 * *$ & -.03 & $.41 * *$ & & & \\
\hline 5. Autonomy frustration & 2.45 & .52 & $.29 * *$ & .00 & $.42 * *$ & $.32 * *$ & & \\
\hline 6. Relatedness frustration & 1.88 & .52 & $.20 * *$ & .08 & $.49^{* *}$ & $.32 * *$ & $.52 * *$ & \\
\hline 7. Competence frustration & 2.49 & .57 & $.17 * *$ & .07 & $.61 * *$ & $.21 * *$ & $.45^{* *}$ & $.50 * *$ \\
\hline
\end{tabular}

Note. $* p<.05$. $* * p<.01$. 
Table 2. Dyadic Polynomial Regression Coefficients and Response Surface Parameters of Adolescent-Reported and Mother-Reported

Overprotection in the Prediction of Internalizing and Externalizing Problems and Psychological Need Frustration

\begin{tabular}{|c|c|c|c|c|c|}
\hline Polynomial regression coefficients & $\begin{array}{c}\text { Internalizing } \\
\text { problems }\end{array}$ & $\begin{array}{l}\text { Externalizing } \\
\text { problems }\end{array}$ & $\begin{array}{l}\text { Autonomy } \\
\text { frustration }\end{array}$ & $\begin{array}{l}\text { Relatedness } \\
\text { frustration }\end{array}$ & $\begin{array}{c}\text { Competence } \\
\text { frustration }\end{array}$ \\
\hline$b_{1}$ - adolescent report & $.07 *$ & $.04 * *$ & $.13 * *$ & $.10 * *$ & .06 \\
\hline$b_{2}-$ mother report & .03 & -.01 & -.06 & -.01 & .03 \\
\hline$b_{3}$ - adolescent report $^{2}$ & .02 & .01 & .02 & -.02 & .02 \\
\hline$b_{4}$ - adolescent $\times$ mother report & -.01 & -.03 & -.04 & .01 & -.08 \\
\hline$b_{5}-$ mother report ${ }^{2}$ & -.01 & .00 & -.02 & -.04 & -.01 \\
\hline \multicolumn{6}{|l|}{ Response surface parameters } \\
\hline$a_{1}$ - slope along $\operatorname{LOC}(\mathrm{x}=\mathrm{y})$ & $.10 * *$ & $.03^{*}$ & .07 & $.09 *$ & $.09^{*}$ \\
\hline$a_{2}$ - curvature along $\operatorname{LOC}(\mathrm{x}=\mathrm{y})$ & .00 & -.02 & -.04 & -.04 & $-.07 *$ \\
\hline$a_{3}$ - slope along LOIC $(\mathrm{x}=-\mathrm{y})$ & .04 & $.05 *$ & $.19 * *$ & $.11 *$ & .03 \\
\hline$a_{4}$ - curvature along LOIC $(\mathrm{x}=-\mathrm{y})$ & .02 & .04 & .04 & -.06 & .09 \\
\hline
\end{tabular}

Note. Non-standardized coefficients are presented. Age and gender were controlled for, throughout the analyses. $* p<.05$. ** $p<.01$. 
Figures

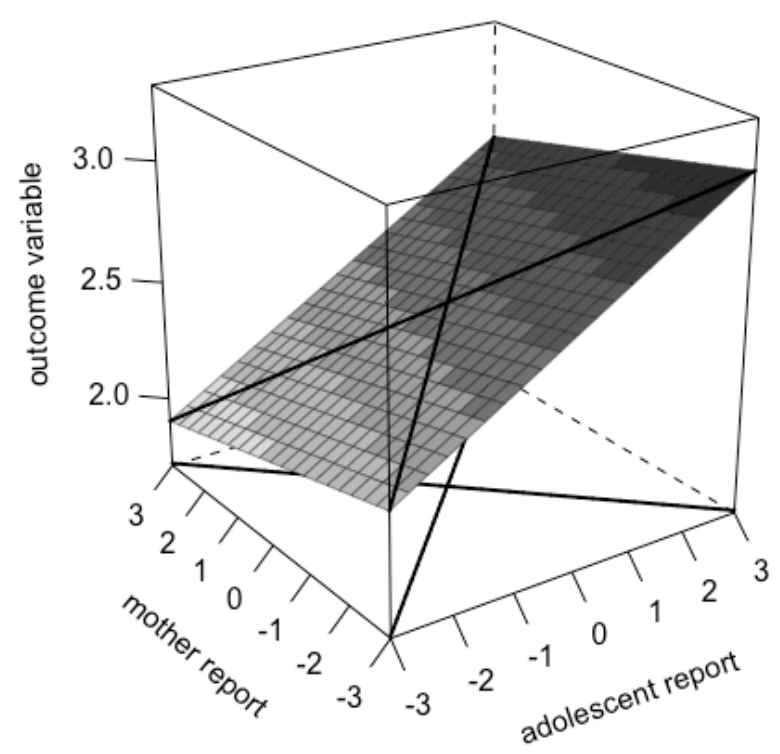

Figure 1. Hypothetical Response Surface, with a Linear and Positive Effect Along the LOC, and a Linear and Positive Effect Along the LOIC

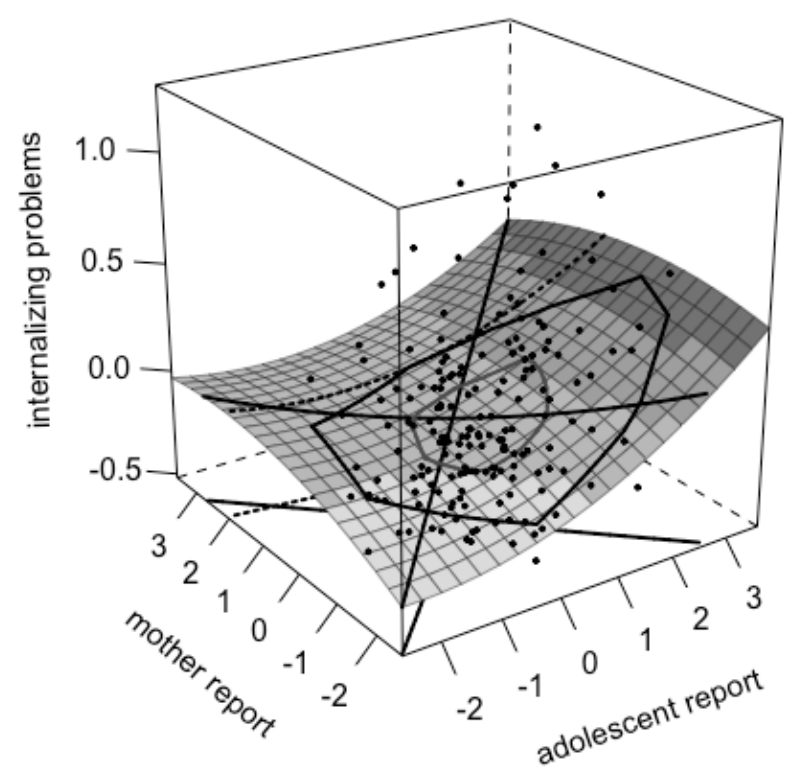

Figure 2. Response Surface for the Polynomial Regression of Overprotective Parenting Predicting Adolescent Internalizing Problems 


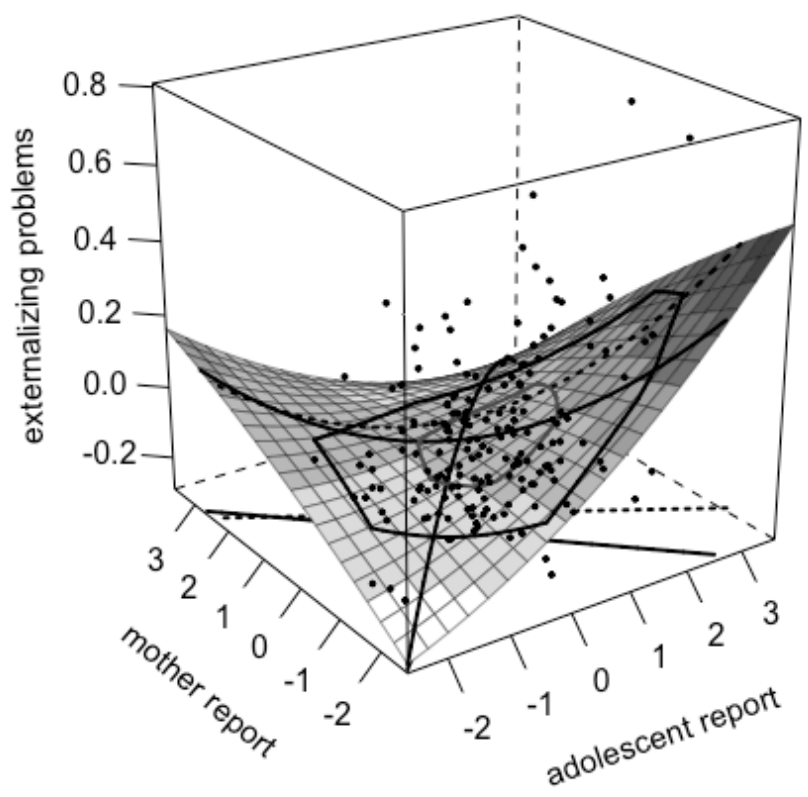

Figure 3. Response Surface for the Polynomial Regression of Overprotective Parenting Predicting Adolescent Externalizing Problems

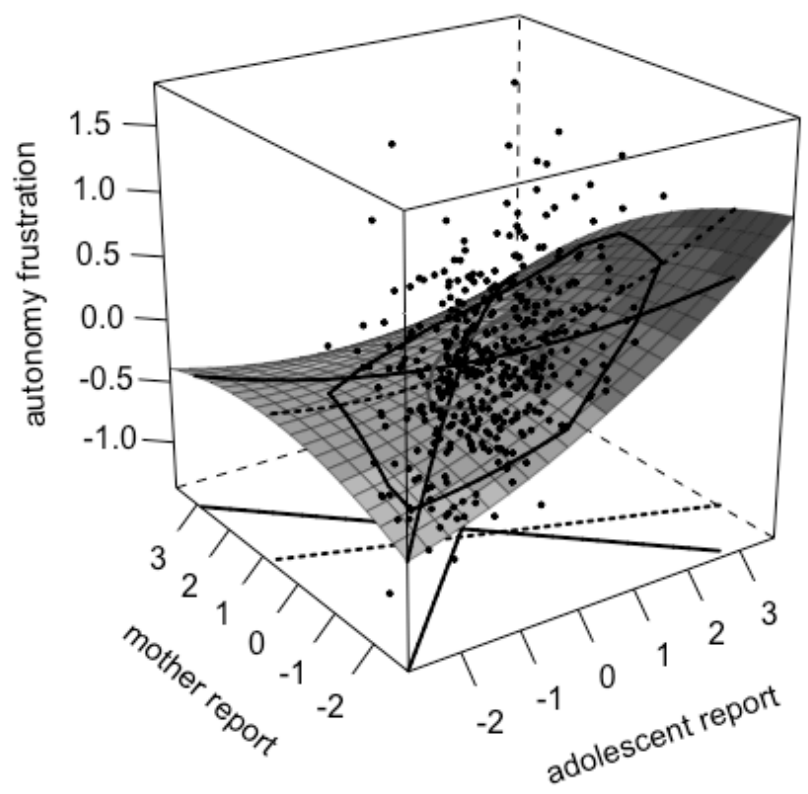

Figure 4. Response Surface for the Polynomial Regression of Overprotective Parenting Predicting Adolescent Autonomy Frustration 


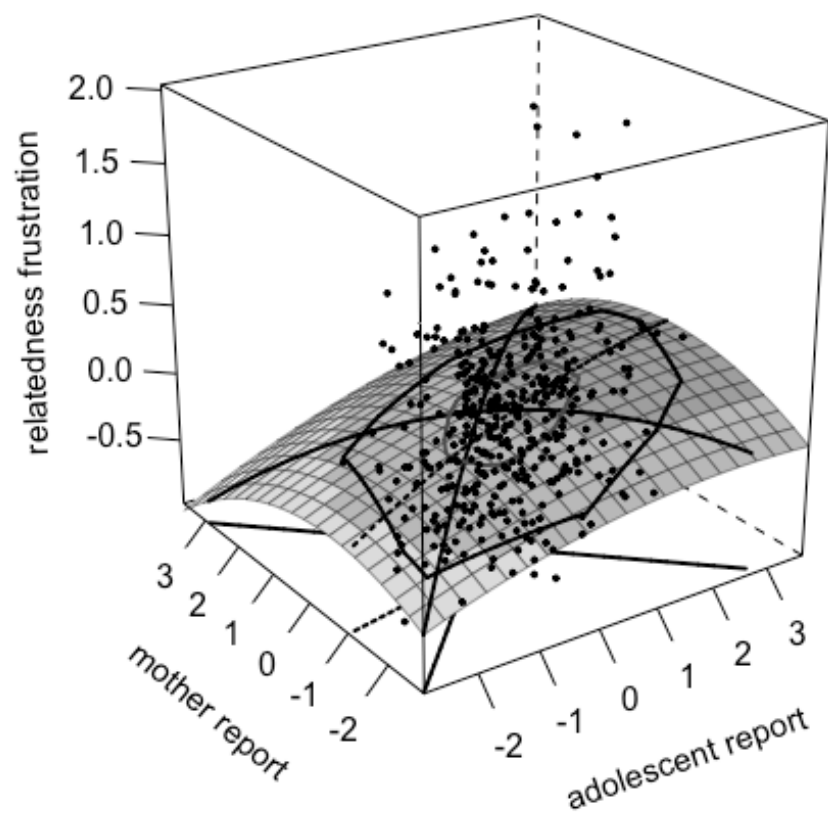

Figure 5. Response Surface for the Polynomial Regression of Overprotective Parenting Predicting Adolescent Relatedness Frustration

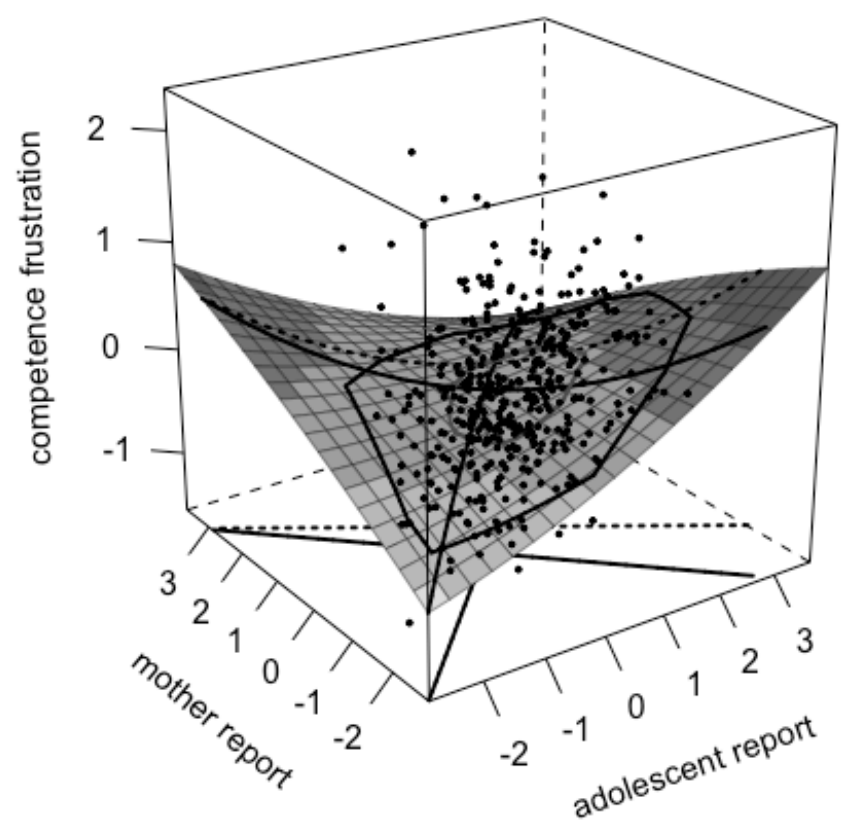

Figure 6. Response Surface for the Polynomial Regression of Overprotective Parenting Predicting Adolescent Competence Frustration 